Volume 3, Number 1, 2017

\title{
Research and Analysis of Rapidly Changing Gas Flow Temperatures Measurement Methods
}

\author{
Vasyl Fedynets, Leonid Lesovoi, Bohdan Chaban* \\ Lviv Polytechnic National University, 12 S. Bandery St, Lviv, 79013, Ukraine
}

Received: April 27, 2017. Revised: May 26, 2017. Accepted: June 02, 2017.

\begin{abstract}
(C) 2017 The Authors. Published by Lviv Polytechnic National University.
\end{abstract}
\begin{abstract}
The temperature of a transducer sensitive element, as a result of its heat capacity, will always lag behind the temperature of the gas flow if this temperature changes. When measuring the flow temperature that varies in time, the transducer doesn't follow the changes in temperature immediately because its sensitive element temperature changes after some time. The distortions of the transducer readings are caused by the thermal inertia due to non-stationary heat processes in the transducers, as well as between transducer and the environment. Since complete elimination of real temperature transducer inertia is not possible, the transducers with some finite values of the thermal inertia are used at practice to measure the varying gas flow temperature. The necessary information about the flow temperature can be obtained by analyzing the record of the non-stationary measurement process. In this case a direct calculation of the flow temperature is made or a correction of the temperature transducer readings delay is made. The results of research and analysis of measurement methods of rapidly changing gas flow temperatures by the direct calculation of the flow temperature and by correcting the temperature transducer readings are presented in this paper.
\end{abstract}

Keywords: gas flow; measurement; heat exchange; temperature; temperature transducer.

\section{Introduction}

The peculiarities of the gas flow temperature measurement conditions are determined by the variety of technological objects that are used in the industrial production, by the physical and chemical properties of the fluids, by the flow velocity, range of temperature measurement, the requirements to the accuracy and reliability of measurement results, the nature of the technological process flow and by the possible distortions in the technological process. Measurement of rapidly changing temperature that varies by the periodic and usually harmonious laws is necessary for many processes. The temperature variations and simultaneous flow velocity variations, that cause variations of convective heat transfer coefficients, are dependent on the operating modes of the technological equipment.

During measurement of flow temperature that varies in time, the transducer doesn't follow the change of temperature as a result of certain values of the thermal inertia, which depends on the geometric shape and dimensions of the sensitive element, heat capacity, density of the sensitive element material and heat transfer coefficient between the flow and the transducer. The necessary information about the flow temperature at such measurements can be obtained by analyzing the record of the non-stationary measurement process. In this case a direct calculation of the flow temperature is made or a correction of the temperature transducer readings delay is made.

The direct calculation method (the method of unsteady process record analysis) is used in cases when the coefficient of heat transfer between the gas flow and temperature transducer can be determined. However, in some cases it is practically impossible to define the heat transfer coefficient between the flow and the transducer in difficult measuring conditions (e.g. in the wall layer of a gas flow or in the shock tube). That is why application of the direct calculation method in these cases is impossible.

\footnotetext{
*Corresponding author. Email address: b.chaban.91@gmail.com
}

This paper should be cited as: V. Fedynets, L. Lesovoi, B. Chaban. Research and Analysis of Rapidly Changing Gas Flow Temperatures Measurement Methods. Energy Eng. Control Syst., 2017, Vol. 3, No. 1, pp. 29 - 36. https://doi.org/10.23939/jeecs2017.01.029 
The analytical dependences for determining the real value of gas flow temperature that varies in time are derived from the theory of regular thermal regime [1,2]. The theoretical and experimental investigations related to this problem were conducted by analyzing the fundamental works [3-9], which are still relevant now, but have become a bibliographical rarity. This kind of research was also conducted by the authors.

The purpose of the research is to investigate the methods for measuring the rapidly changing gas flow temperature by the direct calculation of the flow temperature and by the correction of the readings delay of the temperature transducers as well as to develop the recommendations for their practical application.

\section{Method of unsteady process record analysis}

The direct calculation method (the method of unsteady process record analysis) is used in cases where we can determine the coefficient of heat transfer between the gas flow and temperature transducer.

Let us consider the heat balance during the period of time $\mathrm{d} \tau$ for a cylindrical temperature transducer in the gas flow when the losses due to thermal conductivity can be neglected [1].

The heat flow from the gas stream $Q_{1}$ is defined as

$$
Q_{1}=\left(t_{0}-t_{n}\right) \cdot \alpha \cdot \pi \cdot d \cdot l \cdot d \tau,
$$

where $d$ and $l$ are the diameter and the length of the transducer; $t_{o}$ is the temperature of the gas flow; $t_{n}$ is the temperature of the transducer sensitive element.

The heat absorbed by the transducer

$$
Q_{2}=\frac{d t_{n}}{d \tau} \cdot \frac{\pi d^{2}}{4} \cdot l \cdot \rho \cdot c \cdot d \tau,
$$

and the heat radiated by the transducer

$$
Q_{3}=\sigma \varepsilon \cdot\left[\left(\frac{T_{n}}{100}\right)^{4}-\left(\frac{T_{c m}}{100}\right)^{4}\right] \cdot \pi \cdot d \cdot l \cdot d \tau,
$$

where $\rho$ is the average density of the transducer sensitive element; $T_{n}$ is thermodynamic temperature of the sensitive element; $T_{c m}$ is the thermodynamic temperature of the wall on which the transducer is mounted; $c$ is the average heat capacity of the temperature transducer; $\sigma$ is the Stefan-Boltzmann constant; $\varepsilon$ is the coefficient of surface blackness of the temperature transducer.

On the basis of the energy conservation law we can find that

$$
t_{0}=t_{n}+\frac{1}{\alpha} \cdot\left\{\frac{\rho \cdot d \cdot c}{4} \cdot \frac{d t_{n}}{d \tau}+\sigma \cdot \varepsilon \cdot\left[\left(\frac{T_{n}}{100}\right)^{4}-\left(\frac{T_{c m}}{100}\right)^{4}\right]\right\} .
$$

If we define graphically the derivative $d t_{n} / d \tau$ from the record of the unsteady process through small intervals of temperature variation, and all the other terms in (4) are known, then the temperature of the gas flow can be determined. If there is a need to take into account the variation of heat exchange conditions and variation of transducer internal properties during the temperature measurement process, then the information from one transducer being applied in ordinary measurement schemes is not sufficient. Much more information should be available.

That is why the method of two or three transducers is applied for measurement of the rapidly changing temperatures by means of the inertial transducers. The scheme of non-stationary temperature measurement with application of two temperature transducers is shown in Fig. 1.

The principle of the measurement method with application of two temperature transducers is based on (4), where $\alpha$ i $t_{o}$ are unknown quantities. After writing down the heat balance equation for each of the transducers with the diameters $d_{1}$ and $d_{2}$ respectively we obtain:

$$
t_{0}-t_{n 1}=\frac{1}{\alpha_{1}} \cdot\left\{\frac{\rho_{1} \cdot c_{1} \cdot d_{1}}{4} \cdot \frac{d t_{n 1}}{d \tau}+\sigma \varepsilon \cdot\left[\left(\frac{T_{n 1}}{100}\right)^{4}-\left(\frac{T_{c m}}{100}\right)^{4}\right]\right\},
$$




$$
t_{0}-t_{n_{2}}=\frac{1}{\alpha_{2}} \cdot\left\{\frac{\rho_{2} \cdot c_{2} \cdot d_{2}}{4} \cdot \frac{d t_{n_{2}}}{d \tau}+\sigma \varepsilon \cdot\left[\left(\frac{T_{n_{2}}}{100}\right)^{4}-\left(\frac{T_{c m}}{100}\right)^{4}\right]\right\},
$$

where subscripts 1 and 2 here and further refer to the first and the second transducer respectively.
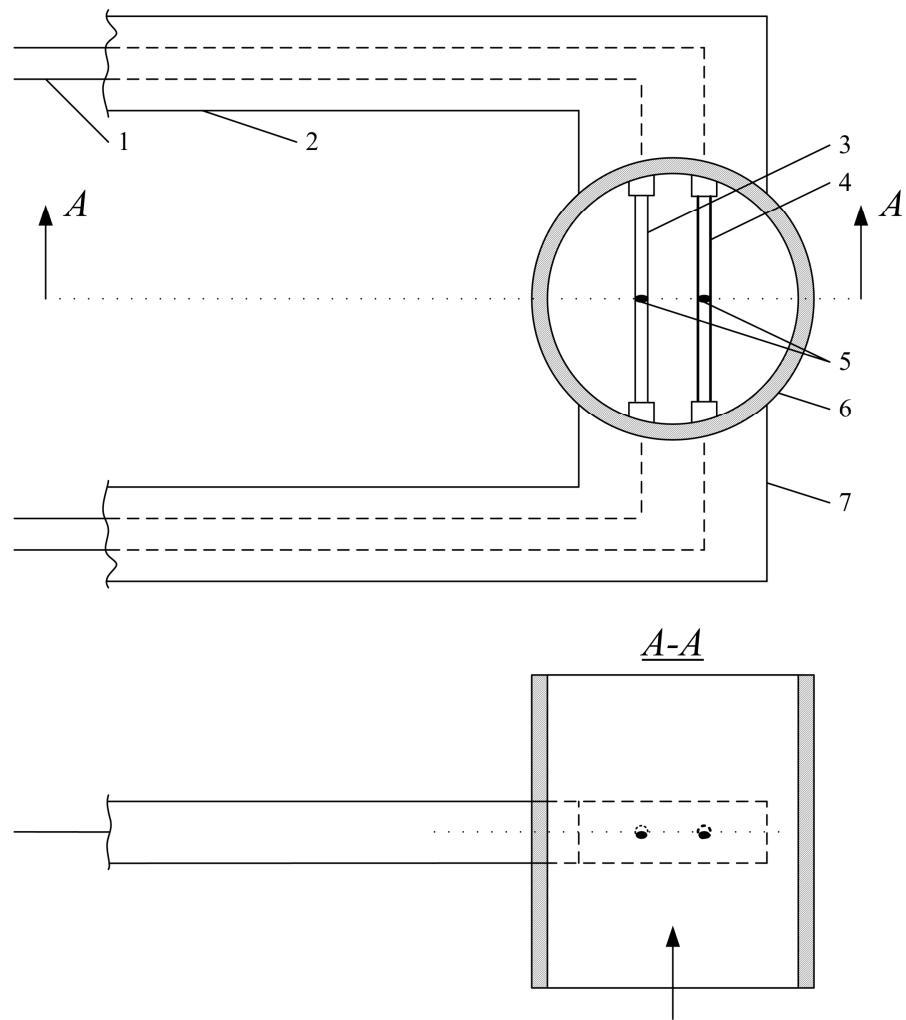

Fig.1. Scheme of a two-element temperature transducer: 1 - outputs to the recording device; 2 - holder; 3 - solid temperature transducer; 4 - hollow temperature transducer; 5 - spikes of thermocouples; 6 - protective screen; 7 - ceramic insulator.

If we express the dependence of heat transfer coefficient as a function of Reynolds number Re, then Nusselt number will be $N u=A \cdot(R e)^{m}$, where $A$ and $m$ are constants. Then

$$
\alpha_{1}=\frac{A \cdot \lambda}{d_{1}} \cdot\left(\frac{V \cdot d_{1}}{v}\right)^{m} ; \alpha_{2}=\frac{A \cdot \lambda}{d_{2}} \cdot\left(\frac{V \cdot d_{2}}{v}\right)^{m} ; \frac{\alpha_{1}}{\alpha_{2}}=\left(\frac{d_{2}}{d_{1}}\right)^{1-m} .
$$

Dividing (6) by (5) with taking into account the ratio (7) we find:

$$
\left.t_{0}=t_{n 1}+\left(t_{n 1}-t_{n 2}\right) \cdot\left\{1 /\left(\frac{d_{2}}{d_{1}}\right)^{1-m} \frac{\frac{\rho_{2} \cdot c_{2} \cdot d_{2}}{4} \cdot \frac{d t_{n 2}}{d \tau}+\sigma \varepsilon \cdot\left[\left(\frac{T_{n 2}}{100}\right)^{4}-\left(\frac{T_{c m}}{100}\right)^{4}\right]}{\frac{\rho_{1} \cdot c_{1} \cdot d_{1}}{4} \cdot \frac{d t_{n 1}}{d \tau}+\sigma \varepsilon \cdot\left[\left(\frac{T_{n 1}}{100}\right)^{4}-\left(\frac{T_{c m}}{100}\right)^{4}\right]}\right)-1\right\}
$$

If we accept that the radiation may be neglected [2] then (8) can be written as: 


$$
\left.t_{0}=t_{n 1}+\left(t_{n 1}-t_{n 2}\right) \cdot\left\{1 /\left(\frac{d_{2}}{d_{1}}\right)^{1-m} \cdot \frac{\frac{\rho_{2} \cdot c_{2} \cdot d_{2}}{4} \cdot \frac{d t_{n 2}}{d \tau}}{\frac{\rho_{1} \cdot c_{1} \cdot d_{1}}{4} \cdot \frac{d t_{n 1}}{d \tau}}\right)-1\right\}
$$

If two identically oriented transducers with the same external diameters are installed in a gas flow then the heat transfer coefficient $\alpha$ will be equal for both of them [1]. If the heat capacities of the transducers are different, then (9) for determining the temperature of the gas flow will look like

$$
t_{0}=t_{n 1}+\left(t_{n 1}-t_{n 2}\right) \cdot\left\{\frac{1}{K \cdot \frac{d t_{n 2} / d \tau}{d t_{n 1} / d \tau}}-1\right\}
$$

where $K=\frac{\rho_{2} \cdot c_{2}}{\rho_{1} \cdot c_{1}}$ which describes the ratio of the thermal inertia of the two temperature transducers.

Different heat capacities of the transducers can be obtained by using a solid and a hollow sensitive elements or make them out of different materials. It is shown in [3] that the highest measurement accuracy is achieved if $K$ value is in the range of $0<K<0.5$.

During deriving the equations presented above it was assumed that the flow regime was the same for both of the transducers, i.e. index $m$ is the same for both of the transducers.

By recording the measured values $t_{n 1}$ and $t_{n 2}$ of the temperature transducers and by determining the rates of the temperature signals change the actual temperature of the gas flow can be calculated if the value of coefficient $K$ is known. The advantage of the measurement method using two transducers is that we don't need to know the absolute value of the coefficient of heat exchange to find the actual flow temperature or the error of its determination. The systematic and random variations of the heat exchange coefficients do not make any influence on the coefficient $K$. And in case of application of a single temperature transducer it would be difficult or impossible to take these variations of the heat exchange coefficient into account.

In [4] method of measurement with simultaneous use of three temperature transducers to improve the accuracy of temperature measurement of gas flows was proposed. The principle of this method is that if all the temperature transducers are made of the same material and are solid cylinders of different diameters, then for each of them the heat balance equation can be written as

$$
t_{0}-t=\frac{1}{\alpha} \cdot\left(\frac{\rho \cdot c \cdot d}{4} \cdot \frac{d t}{d \tau}\right)
$$

The heat transfer coefficient for each transducer can be presented as

$$
\alpha=a \cdot d^{m-1},
$$

where $a$ is a constant number.

Taking into account the fact that for Reynolds numbers from 5,000 to 50,000 (the conditions for measurement of a gas flow temperature) the value of the constant $m$ is approximately equal to 0.5 , and substituting (12) to (11) we obtain the equation for determining the temperature of any of the three transducers

$$
t_{n}=-b \cdot d^{2-m} \cdot \frac{d t_{n}}{d \tau}-t_{0}
$$

where $b$ is a constant number. 
If we build a curve of $t_{n}$ dependence on $d^{2-m} \cdot\left(\frac{d t_{n}}{d \tau}\right)$ then at any time for the three transducers we obtain points which are placed in a straight line, which will overlap with the axis of ordinates in point $t_{n}=t_{0}$. Since this method is a graphical one, we can smooth out errors of individual measurements.

The heat transfer coefficient between the flow and the transducer in some complicated measuring conditions, such as in a wall layer of the gas flow or in the shock tube, cannot be defined so application of the method of direct calculation is impossible.

\section{Method of correction of the temperature transducer readings delay}

Correction of the temperature transducer readings delay is described in the works $[5,6]$. There are the results of gas temperature profile measurement by means of a transducer moving with a constant speed presented in these works.

This method can be used to measure the flow stagnation temperature distribution down the thickness of the turbulent wall layer of a gas flow. If a step change of temperature $t_{0}$ takes place in a turbulent wall layer the sensitive element of the temperature transducer will get some portion of heat $d Q$ during a time period $d \tau$ which can be described by the following equation

$$
d Q=\alpha F\left(t_{0}-t_{n}\right) d \tau
$$

where $\alpha$ is the heat transfer coefficient from the gas flow to the sensitive element of the transducer; $F$ is the sensitive element area; $t_{n}$ is the sensitive element temperature.

This quantity of heat will lead to the temperature $t_{n}$ increase by

$$
d Q=C M d t_{n},
$$

where $C$ is the heat capacity of the sensitive element material; $M$ is the sensitive element mass.

From (14) and (15) we get

$$
C \cdot M \frac{d t}{d \tau}=\alpha \cdot F \cdot\left(t_{0}-t_{n}\right)
$$

Taking into account that

$$
\frac{d t}{d \tau}=\frac{d t}{d y} \cdot \frac{d y}{d \tau}=y^{\prime} \frac{d t}{d y}
$$

equation (16) can be represented as follows

$$
C \cdot M \cdot y^{\prime} \cdot \frac{d t_{H}}{d y}=\alpha \cdot F \cdot\left(t_{\mathrm{ycr}}-t_{H}\right)
$$

where $y$ is the wall layer thickness; $y^{\prime}=\frac{d y}{d \tau}$ is the transducer velocity in the turbulent wall layer; $t_{y c m}$ is the temperature measured by the transducer in a steady mode of gas flow; $t_{t}$ is the temperature measured by the transducer in an unsteady mode of gas flow.

After differentiating (18) by $y$ and taking into account that the heat transfer coefficient varies across the wall layer thickness, i.e. $\alpha=\alpha(y)$, we get

$$
\frac{d t_{y c m}}{d y}=\left[1-\frac{k_{1}}{\alpha^{2}} \cdot \frac{d \alpha}{d y}\right] \cdot \frac{d t_{H}}{d y}+\frac{k_{1}}{\alpha} \cdot \frac{d^{2} t_{H}}{d y^{2}}
$$

where $k_{l}$ is a constant. 
Assuming that the last term of (19) is small compared to the other terms, we obtain the equation

$$
1-\frac{k_{1}}{\alpha^{2}} \cdot \frac{d \alpha}{d y}=\frac{\frac{d t_{y}}{d y}}{\frac{d t_{H}}{d y}} .
$$

This equation can be used for making a correction of the temperature transducer readings delay.

In order to measure the temperature in very short-term processes, such as shock tube, a method, in which the temperature of the gas flow is determined by the change of the sensitive element transducer temperature in time, was used in [7]. Tungsten filament with a diameter of $0,005 \mathrm{~mm}$ and a length of $3 \mathrm{~mm}$ was used as a sensitive element. According to this method a small electric current $(5 \mathrm{~mA})$ is passed through the filament at the beginning of the experiment to measure the electrical resistance of the filament. After that, the tungsten filament is introduced into a gas flow and begins to take some heat from the flow (see. Fig. 2).

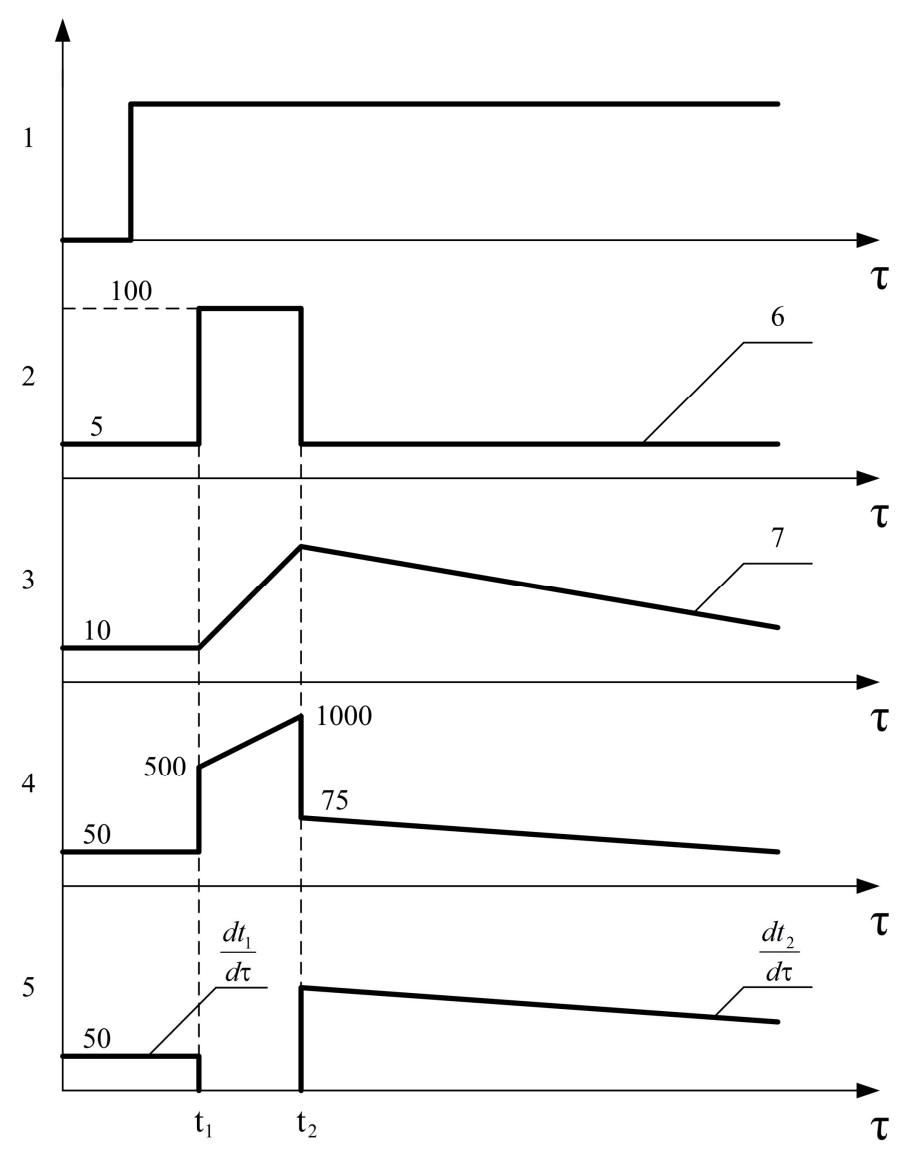

Fig.2. The sequence of the processes during the gas flow measurement by means of a temperature transducer with an impulse mode of filament heating: 1 - a flow parameter; 2 - electric current flowing through filament, $\mathrm{mA} ; 3$ - filament resistance, $\Omega ; 4$ voltage across the filament, $\mathrm{mV} ; 5$ - the output signal of the filament, $\mathrm{mV} ; 6$ - electrical power impulse; 7 - combined effect of heat input from the gas flow to the filament and loss of heat from the filament to the filament holders.

During the next step a short impulse of electrical power, with a duration of $\Delta \tau\left(\Delta \tau=\tau_{1}-\tau_{2}\right)$, is supplied to the filament in the time moment $\tau_{1}$ which leads to an abrupt raise of the filament temperature to the value $t_{2}$. After the impulse the change of the filament temperature in time is recorded again with a small electric current flowing through the filament. The heat balance equation for the filament at the time moment $\tau_{l}$ can be written as

$$
\frac{d t_{1}}{d \tau}=K \cdot\left(t_{p}-t_{1}\right)+\frac{1}{M \cdot C \cdot L} \cdot Q_{B}
$$


where $K$ is the coefficient inversely proportional to the time constant; $t_{p}$ is the equilibrium temperature of the filament; $M, C, L$ are the weight, the specific heat capacity and the length of the filament respectively; $Q_{B}$ is the heat loss from the filament to the defensive fitting of the transducer.

The equation for the moment of time $\tau_{2}$ can be similarly written as

$$
\frac{d t_{2}}{d \tau}=K \cdot\left(t_{p}-t_{2}\right)+\frac{1}{M \cdot C \cdot L} \cdot Q_{B}
$$

Based on the results of the experimental research carried out by the authors it was defined that that the last term in the equation (21) is insignificant compared to the term $K=\left(t_{p}-t_{l}\right)$ at the time moment $\tau_{l}$ and the value of the term $\frac{1}{M \cdot C \cdot L} \cdot Q_{B}$ in (22) is considerable compared to the previous term at the time moment $\tau_{2}$ and it cannot be ignored. This provides the possibility to determine the heat loss $Q_{B}$ by making an individual test before the experiment by supplying an electric impulse to the filament in a vacuum and recording the filament temperature variation. The value $Q_{B}$ is determined by the following equation

$$
Q_{B}=M \cdot C \cdot L \cdot \frac{d t_{B}}{d \tau} .
$$

By substituting (23) for $Q_{B}$ into (21) and (22) we obtain the actual temperature of the filament

$$
t_{p}=t_{2}+\left(t_{2}-t_{1}\right) \cdot \frac{\frac{d t_{2}}{d \tau}-\frac{d t_{B}}{d \tau}}{\frac{d t_{1}}{d \tau}+\frac{d t_{B}}{d \tau}-\frac{d t_{2}}{d \tau}} .
$$

The values $t_{1}, t_{2}, d t_{1} / d \tau, d t_{2} / d \tau$ are measured during the experiment. And the value $d t_{B} / d \tau$ is defined during an individual test in a vacuum before the experiment.

There are also other methods of introducing corrections into the readings of the inertial temperature transducers $[8,9]$. These methods however are not widely used which is caused by the expensive equipment and complexity of measurements at practice.

The reduction of the thermal inertia of the temperature transducers is limited by the heat transfer conditions and by the requirements to the mechanical strength of the transducers. The structure of the measuring circle can be changed by introducing a corrective device into it in order to increase the transducer's speed of response for a short-term measurement of flow temperature. The series electric correction devices are most often applied at practice. These devices are shown in Fig. 3.

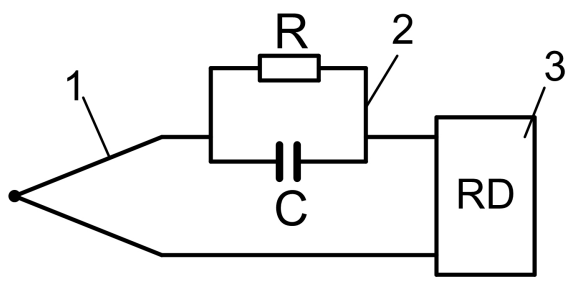

a) thermocouple with an $\mathrm{RC}$ circuit.

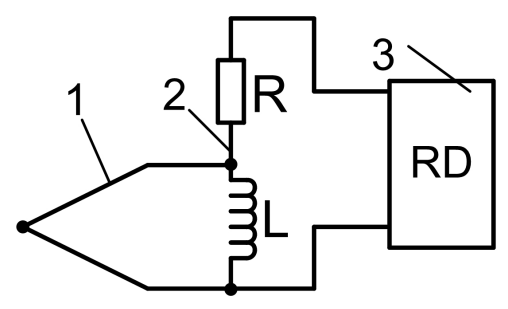

b) thermocouple with an RL circuit.

Fig.3. The simplified scheme of a temperature transducer with a correction device: 1 - a thermocouple; 2 - an electric correction circuit; 3 - a recording device $\mathrm{RD}$.

By choosing the values for the parameters of the correction device the speed of the measuring circle can be increased significantly and the frequency range of its work can be widened. In other words, introduction of a corrective device leads to the same result as application of a less inertial temperature transducer. 
Correction devices provide the possibility of the gas flow temperature measurement during the time interval considerably shorter than the time constant of the temperature transducer. Therefore, the schemes of the temperature transducers with the correction devices are often used when it is necessary to make a short-term high temperature measurement in a flow with the temperature that exceeds the allowable range for the transducer.

\title{
4. Conclusion
}

The methods for measurement of rapidly changing temperature of gas flows are analyzed in this paper. The conditions for application of the flow temperature direct calculation method are defined. The conditions for making a correction of the temperature transducer readings delay due to a finite value of the transducer thermal inertia are defined.

It should be noted that some of the measurement methods did not receive a widespread use due to the high cost of the equipment and the difficulty of measurements at practice. Most of the methods mentioned above can be applied during the experimental study of new devices and during research in the field of gas flow temperature measurement.

\section{References}

[1] Moffat, R. J. (1962). Gas Temperature Measurement. Temperature: Its Measurement and Control in Science and Industry, 3(2), 321.

[2] Vas, I. E. (1972). Flow Field Measurements Using Total Temperature Probe at Hypersonic Speeds. AIAA, 10(3), $317-323$.

[3] Giedt, W. H., Chambers, J. T.-A. (1965). Dual-Element Transducer for Measuring High Gas-Stream Temperatures. Heat Transfer, 87(3), $397-402$.

[4] Benson, R. S., Brundrett, G. W. (1966). Development of resistance wire thermometer for measurement of the transient temperatures in exhaust system of internal combustion engines. Measurement of transient temperature and heat flux. Reinhold Publ. Co., 56-91.

[5] Kilburg, H. P. (1968). A High Response Probe for Measurement of Total Temperature and Totalpressure Profiles through a Turbulent Boundary Layer with Heat Transfer in Supersonic Flow. AIAA, 9.

[6] Alverman, W. (1986). Determination of temperature profiles by means of thermocouples. Ztschr. fur Plugwissenschaften, 4, $179-183$.

[7] Softley, E. J. (1968). Use of a Pulse Heated Fine Wire Probe for the Measurement of Total Temperature in Shock Driven Facilities. AIAA, 12 .

[8] Quamby, A. (1984). Transcient Response of Wire Resistance Thermometers. RAS, 646, 696-698.

[9] Basic Theory of Millisecond Response Thermocouples (1970). Instrument Practice, 10, 687-691.

\section{Дослідження та аналіз методів вимірювання швидкозмінних температур газових потоків}

\author{
Василь Фединець, Леонід Лесовой, Богдан Чабан \\ Національний університет «Львівська політехніка», вул. С. Бандери, 12, Львів, 79013, Украӥна
}

\begin{abstract}
Анотація
Внаслідок певного значення теплоємності чутливого елемента перетворювача температури його температура завжди буде відставати від температури газового потоку, якщо вона змінилася. При вимірюванні змінної в часі температури потоку перетворювач також не встигає слідкувати за зміною температури, оскільки для зміни температури його чутливого елемента потрібен деякий час. Спотворення показів перетворювача через нестаціонарності теплових процесів як в самому перетворювачі, так і між перетворювачем і навколишнім середовищем обумовлені його тепловою інерцією. Оскільки повного уникнення інерційності реального перетворювача температур досягнути неможливо, при практичних вимірюваннях температур газового потоку, що змінюються в часі, використовують перетворювачі, які мають деяке скінченне значення показника теплової інерції. При таких вимірюваннях отримувати потрібну інформацію можливо шляхом аналізу запису самого нестаціонарного процесу вимірювання здійснюючи прямий розрахунок температур середовища, або вносити поправку на запізнення в покази перетворювача температур.В статті проведено дослідження та аналіз методів вимірювання швидкозмінних температур газових потоків шляхом їх прямого розрахунку та введенням поправки в покази перетворювачів температури.
\end{abstract}

Ключові слова: газовий потік; вимірювання; теплообмін; температура; перетворювач температури. 